\title{
EVALUATION OF DRAIN COVERINGS DESIGN IN EL-SHARKIA GOVERNORATE, EGYPT*
}

\author{
Shaimaa M. Khairy ${ }^{+(1)}$, Magdy H. Mowafy ${ }^{(2)}$, Walaa Y. El-Nashar ${ }^{(2)}$ \\ (1) East Delta Drainage Projects Authority, Ministry of Water Resources and Irrigation, Egypt \\ (2) Water Engineering Dept, Faculty of Eng., Zagazig Univ., Egypt
}

\begin{abstract}
Drainage affects a host of biophysical soil properties and strongly influences crop growth and quality. Drainage systems improve field operations, enhance growing conditions for crop production and increase crop yields on poorly drained soils. The main problems which lead to a perceived need to cover a drain are: (i) to minimize the adverse impact of a polluted drain, especially close to residential areas, (ii) need to use the land area occupied by the drain for an access road or some other use, (iii) poor soil stability leading to bank failure, and (iv) to protect them from pollution. The concrete pipes or box sections are used for drain covering.

In this study twenty drain coverings were selected and redesigned as pipe and box types with full and partial flow using Darcy and Hazen-Williams equations. Hydraulic and economic studies were carried out to evaluate these coverings. The best alternative for each covering was chosen from the hydraulic view point, the economic view point and from both the hydraulic and the economic view points together.
\end{abstract}

KEY WORDS: Drain Covering; Pipe Type; Box Type; Full Flow; Partial Flow; Egypt

\section{ÉVALUATION DES COUVERTURES DE VIDANGE CONCEPTION EN EL-SHARKIA GOVERNORATE, EGYPTE *}

\begin{abstract}
RÉSUMÉ
Drainage affecte un grand nombre de propriétés du sol biophysiques et influe sur la croissance des cultures et la qualité fortement. Les systèmes de drainage améliorer les opérations sur le terrain, d'améliorer les conditions de croissance pour la production agricole et d'augmenter les rendements des cultures sur des sols mal drainés . Les principaux problèmes qui conduisent à un besoin perçu pour couvrir un drain sont : ( i ) afin de minimiser l'impact négatif d'un drain pollué, en particulier à proximité des zones d'habitation, ( ii ) la nécessité d' utiliser la superficie occupée par le drain pour un accès route ou un autre usage, ( iii ) la stabilité des sols pauvres conduit à l'échec de la banque, et ( iv ) pour les protéger de la pollution. Les tuyaux en béton ou des caissons sont utilisés pour le revêtement de vidange .

Dans cette étude, vingt revêtements de drainage ont été sélectionnés et remaniés comme les types de tuyaux et de la boîte avec un débit total ou partiel à l'aide de Darcy et Hazen - Williams équations . Études hydrauliques et économiques ont été réalisées pour évaluer ces revêtements. La meilleure alternative pour chaque revêtement a été choisi à partir du point de vue hydraulique, du point de vue économique et de bien l'installation hydraulique et économique vue points.together .
\end{abstract}

MOTS CLÉS : Drain Couvrant ; tuyau type ; Type de boîte ; plein débit ; flux partiel ; Egypte

\footnotetext{
* Received: 4/12/2013, accepted: 19/1/2014, Ref. No. 172, (Original Paper)

+ Contact author (Shasha533@yahoo.com)
} 


\section{EVALUATION OF DRAIN COVERINGS DESIGN IN EL-SHARKIA GOVERORATE, EGYPT}

Khairy, Mowafy, El-Nashar

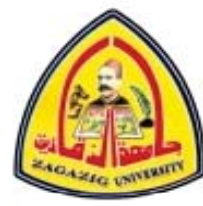

EIJEST

\section{INTRODUCTION}

The covering is closed canal or industrial type (culvert). It is created to pass the discharge of waterway under the road or railway line. Mainly used to pass the small discharge to function as bridge there are two types of covering, the pipe type and the box type. The protection of agricultural drains against pollution resulting from illegal dumping of both liquid and solid wastes in residential areas can be achieved in different ways. The negative impact is the high cost, difficulty of finding an alternative route and encroachment of residential areas to the new drain sites as a result of population growth.

There are a lot of researches about this topic such as Christodoulou [1] studied the losses at drop manholes in supercritical pipelines. He found that the local head-loss coefficient was governed by a dimensional drop parameter, expressed in terms of the drop height and the inflow velocity. Dasika [2] investigated the two equations for rate of flow under inlet control by experiment. His study also recommended that the tail water depth be equal to the diameter of the pipe using a baffle wall. Clarht and Charles [3] did a model to simulate a model for the flow of a slowly-settling suspension being transported in the laminar regime through a pipeline with a constant overall pressure drop by using experimental scaled-down pipeline data. Ferro [4] reported the results of an investigation carried out to test the applicability of the self-similarity hypothesis for determining the flow-resistance law in small-diameter plastic pipes. Hager and Guidice [5] derived dimensionless equations of culvert flows for basic flow types: critical, uniform, gated, and pressurized flows. Bombardelli and Garcia [6] used the HazenWilliams formula for the design of largediameter pipes, without regarding for its limited range of applicability. Brasington and Smart [7] investigated the evolution and dynamics of larger-scale landforms. Lee and Jin [8] developed a computer program for the design of rectangular culverts, which needs a number of iterations for achieving a solution. Tao and Xiyun [9] examined the effectiveness of the approach for predicting the migration of drops in a shear flow and investigated the behavior of the drop migration in the channel flow under zero gravity. American Association of State Highway and Transportation Officials [10] recommended the concept of critical storm duration to estimate a design flood discharge for culvert design. Wood [11] studied the traditional approach to transient analysis might dispute the claim. $\mathrm{Ku}$ and Jun [12] made a computer program that considered non-uniform characteristics of the flow in the culvert by widely adopting new information. Kang et al. [13] recommended the concept of critical storm duration to be appropriate to estimate a design flood discharge for culvert design. Korea Expressway Corporation [14] described hydraulic design procedures for culverts. Fahmy [15] studied the covering of canals and drains, advantages and disadvantages. Vatankhah and Easa [16] used the Manning formula and the attractive force equation as governing equations to design erodible and riprap channels. Colin, Catherine and Fabre [17] experimented on vertical turbulent flow with mill metric bubbles, under three gravity conditions, upward, downward and microgravity flows. Yoo and Lee [18] determined dimensions of a rectangular culvert section, current design approaches by using several trial calculations.

The main objective of this study is evaluating the drains covering in Egypt according to the hydraulic and economic points. Twenty drain coverings are selected from the field then the four alternatives are suggested as pipe and box types, in cases of full and partially flow then the best alternative is chosen according to hydraulic and economic point.

\section{STUDY AREA}

The study area is located in El-Sharkiya which is in the East Delta as shown in Fig. (1), the area of East Delta is about 2,163,331 feddan and lies between $30^{\circ} \mathrm{N}$ to $31^{\circ} 30^{\prime} \mathrm{N}$ and $31^{\circ} 6^{\prime} \mathrm{E}$ to $32^{\circ} 20^{\prime} \mathrm{E}$. In this study, the areas which studied are located in Zagazig, Minya El-Kamh, Diarb Negm, Mashtol ElSook, Kafr Saker, Billbis and Abu Kebir cities. 


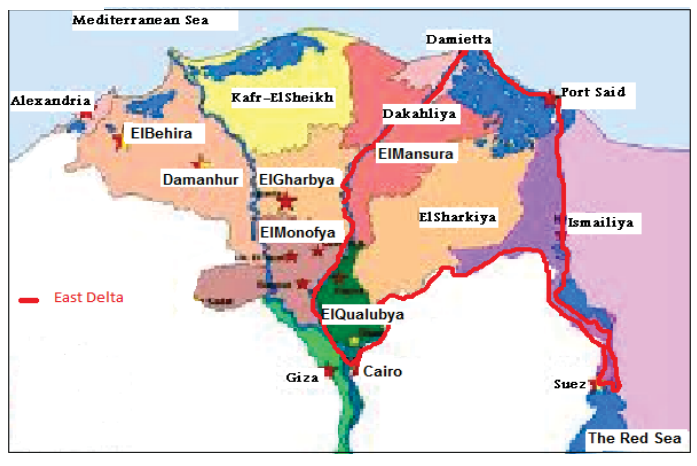

Fig (1): Location Map of the Study area

\section{METHODOLOGY}

The Methodology of this paper is:

1- Collecting the data of selected twenty drain coverings, this data is collected from the field and ministry of water resources and irrigation.

2- The hydraulic evaluation includes hydraulic design and calculation of head losses for pipe and box types with full flow by using Manning equation while Hazen-Williams equation for both pipe and box types with partially flow.

3- The drain coverings -which are constructed in the field as a pipe type - are designed as pipe with full and partially flow then are designed as a box type by calculating the dimensions due to the wetted perimeter of full and partially flow of pipe type then the heading up is calculated.

4- The drains covering - which are constructed in the field as a box type- are designed as box with full and partially flow then designed as a pipe type by calculating the diameter due to the wetted perimeter of full and partially flow of box type then the heading up is calculated.

5- The economic evaluation includes the calculation of the cost of covering for each alternative if it was constructed in the past or if it will be constructed in year 2013 .

6- The best alternative is chosen according to the hydraulic and economic evaluations.

\section{HYDRAULIC EVALUATION}

In general, the design of a waterway covering requires a hydraulic design. The modular design will therefore be related to the design principles and calculations only.

The following items are necessary when designing a waterway covering, for both the pipe and box types:

1. Precise definition of the characteristics of the covered reach, passing flow and the corresponding water levels;

2. Definition of the appropriate features of the vents of the covering as box dimensions or pipe diameter and the number of vents;

3. Computing the generated head losses due to the inlet, friction, elbow, bend, manholes, and the exit structure along the covering path;

4. Defining the setting levels of the upstream and downstream bottom invert levels. Subsequently the levels of the upper ones can be easily determined;

5. Defining the generated upstream and downstream water levels;

6. Checking the effects of the covering construction on the upstream waterway reach.

\subsection{Design Criteria for Drain Covering}

The Design requires extensive data collection and field survey procedures including the following parameters:

* Drain catchment area;

* Longitudinal profile of the drain;

* Drain characteristics;

* The expected flow rate;

* Soil characteristics;

* The location of the drain in relation to a potential solid waste management facility;

* Information on the expected use of the area above the covered drain.

\subsection{Drain Covering Options}

\subsubsection{Pipe type}

This type, which can have one or more vents, is more suitable for waterways with a small discharge. The pipes should be constructed from pre-cast reinforced concrete. The length of the pre-cast units will depend on the pipe diameter and the specification of the reinforcement used. Design of the covering is as a pipe type according to full and partially flows is given as follows:

\section{a- Pipe with Full Flow:}

By using Darcy equation as follow [19]: 


\section{EVALUATION OF DRAIN COVERINGS DESIGN IN EL-SHARKIA GOVERORATE, EGYPT}

Khairy, Mowafy, El-Nashar

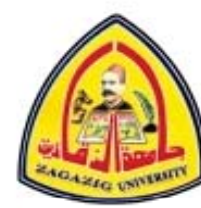

EIJEST

$$
Q=\frac{\pi * D^{2}}{4} * V
$$

Where,

Q: Flow rate in $\mathrm{m}^{3} / \mathrm{s}$;

$V$ : Velocity of flow in $\mathrm{m} / \mathrm{sec}$,

$V_{\text {pipe }}=V_{p}=(2-3) V_{\text {drain }}$;

$D$ : Diameter of pipe in $\mathrm{m}$.

To calculate the heading up (Hl), Darcy equation is used [19]:

$$
\begin{aligned}
& \mathrm{Hl}=h_{1}+h_{2} \\
& h_{1}=\frac{4 * f * L * V_{p}{ }^{2}}{2 * g * D} \\
& h_{2}=\frac{V_{p}^{2}}{2 * g}
\end{aligned}
$$

Where,

Hl: Total heading up (m);

$f$ : Friction factor (dimensionless);

$L$ : Length of covering (m);

$V_{p}$ : Velocity of the flow through the pipe $(\mathrm{m} / \mathrm{sec})$;

$g$ : Gravity acceleration $\left(\mathrm{m} / \mathrm{sec}^{2}\right)$;

$h_{1}$ : Head losses from friction due to full flow (m);

$h_{2}$ : Head losses from velocity (m);

\section{b-Pipe with Partially Flow:}

By using Hazen-Williams equation as follow [19]:

$Q=0.335 * C * D^{0.63} * S^{0.54}$

Where,

C: Pipe roughness coefficient (dimensionless) $=130-140$;

$D$ : Pipe diameter in $(\mathrm{m})$;

$S$ : Slope of hydraulic grade line, dimensionless.

To calculate the heading, Hazen-William equation is used [19].

The total head $\left(\mathrm{H}_{\mathrm{par}}\right)=h_{\text {ppart }}+h_{2 p a e} .(6)$

$$
\begin{aligned}
& h_{1 \text { part }}=\frac{0.002083 L}{D^{4.8655}}\left(\frac{100 Q}{C}\right)^{1.85} . \\
& h_{2 \text { part }}=\frac{V_{p}^{2}}{2 * g} \ldots \ldots \ldots \ldots \ldots \ldots . .(8)
\end{aligned}
$$

Where,

$h_{1 p a r t}$ Head losses from friction due to partially flow (m); $h_{2 p a r t}:$ Head losses from velocity (m);

\subsubsection{Box Type}

In this type, the cross section of the vent can be rectangular or square and can have one or more vents. Box section covering is appreciably more costly than the pipe. It has the benefit that it is more suitable for higher flow rates, although the cost per square meter of cross section is still higher than for pipes. It is also stronger, being constructed from reinforced concrete, and therefore more suitable if the covered area is expected to be subjected to heavy loading, for example if it is to be used as a road.

To design the box type with full and partially flow, the continuity equation is used as follow [20]:

$Q=A^{*} V$

Where,

A: Area of the cross section $=\mathrm{w}^{*} \mathrm{~d}\left(\mathrm{~m}^{2}\right)$;

w: Width of the box cross section (m);

$d$ : Depth of the box cross section (m); $\mathrm{d}=\mathrm{y}+0.5 \mathrm{~m}$;

$y$ : Depth of water (m);

$V$ : Velocity of flow in $\mathrm{m} / \mathrm{sec}, V_{b o x}=(2-3) *$ $\mathrm{V}_{\text {drain }}$

To calculate the heading up for box type $\left(\mathrm{H}_{\text {box }}\right)$, the following equation is used [20]:

$\mathrm{H}_{\mathrm{box}}=h_{f}+h_{e n}$

Where,

$h_{f}$ : Losses due to friction (m); $\quad h_{e n}$ : Losses due to entrance (m);

$$
\begin{aligned}
& h_{f}=L\left(\frac{Q^{*} n}{A * R^{2 / 3}}\right)^{2} \\
& h_{e n}=K_{e n} \frac{V_{e n}^{2}}{2 g} \ldots . .
\end{aligned}
$$

Where,

$n$ : Coefficient of roughness (dimensionless);

$R$ : Hydraulic radius (m);

$K_{e n}$ : Entrance losses coefficient (dimensionless).

$V_{e n}$ : Entrance velocity $(\mathrm{m} / \mathrm{sec})$ 


\section{ECONOMIC EVALUATION}

This part presents the economic evaluation of the covering for different drains. The old and new costs for the redesign as pipe and box type with full and partially flow. The saving money for the four alternatives is calculated. This saving is calculated for different covering which were constructed in the past if it was constructed by the redesign, and if it will be constructed in year 2013 as flowing:

\subsection{Calculation of the Inflation Rate (i):}

The cost of construction of the covering is available in the year which each covering was constructed, to calculate the saving of money if this covering was constructed by the redesign in the past the prices for each diameter in each year must be known. The price of the actual diameter and the price of the same diameter in year 2013 are available, and the inflation rate can be calculated. By using this inflation rate for each year, the price for any new diameter can be calculated, and then the prices for new diameters can be calculated. To calculate inflation rate, the following equation is used [21].

$\mathrm{F}=\mathrm{P}(1+\mathrm{i})^{\mathrm{N}}$

Where,

F: the future worth;

P: the present worth "principal";

$\mathrm{i}$ : inflation rate $(\%)$;

$\mathrm{N}$ : number of years;

\subsection{Money Saving in the Past and in Year 2013:}

Saving of money for box and pipe types which are redesigned with full and partially flow is calculated if the drains covering were constructed in the past and if the drain coverings will be constructed in year 2013.

\section{RESULTS AND DISCUSION}

The analysis of the results includes the analysis of the hydraulic results and the analysis of economic results.

\subsection{Analysis of the Hydraulic Results}

1- For heading up, the best design for all selected drain coverings is the pipe type with partially flow. The values of $(\mathrm{Hl})$ for the selected twenty drains covering are shown in Fig (2).

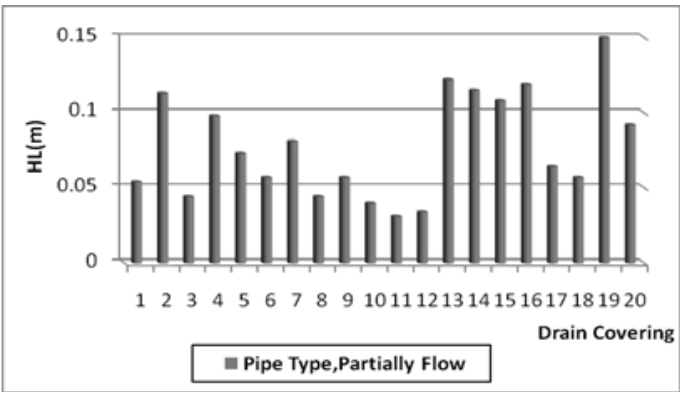

Fig (2): Values of (HI) for Selected Drains Covering

2- For the area of the cross section (A), the best design for all selected drain coverings is pipe type, full flow. The values of (A) are shown in Fig (3).

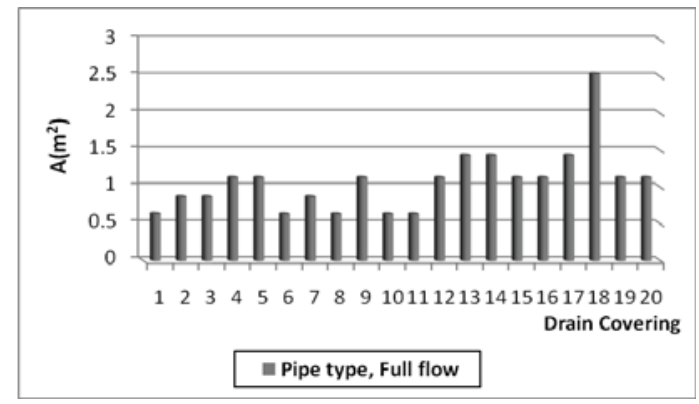

Fig (3): Values of (A) for Selected Drains Covering

3- For hydraulic radius (R), the best design for all selected drains covering is the pipe type with full flow. The values of (R) are shown in Fig (4).

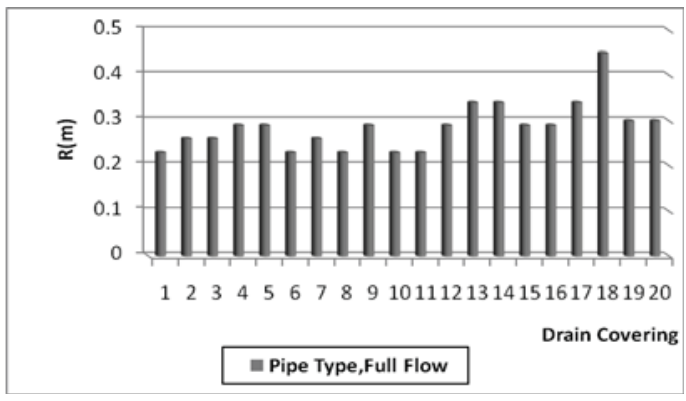

Fig (4): Values of (R) for Selected Drains Covering 


\section{EVALUATION OF DRAIN COVERINGS DESIGN IN EL-SHARKIA GOVERORATE, EGYPT}

Khairy, Mowafy, El-Nashar

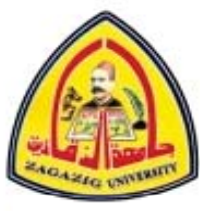

EIJEST

4- For the velocity of the flow (V), the best design for all drain coverings is pipe type, partially flow. The values of (V) are shown in Fig (5).

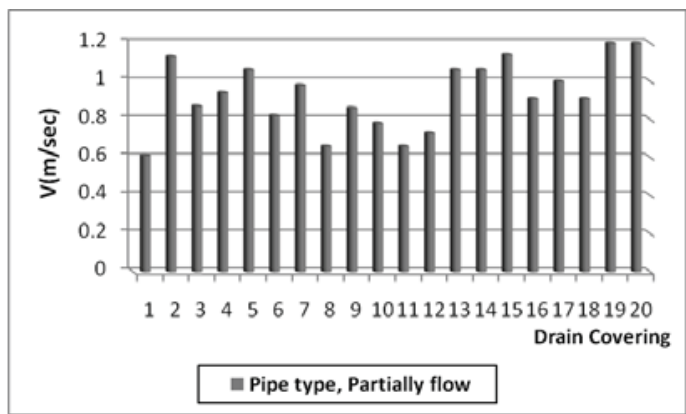

Fig (5): Values of (V) for Selected Drains Covering

5- For the discharge of the flow (Q), the best design for all selected drains covering is the pipe type with partially flow. The values of (Q) are shown in Fig (6).

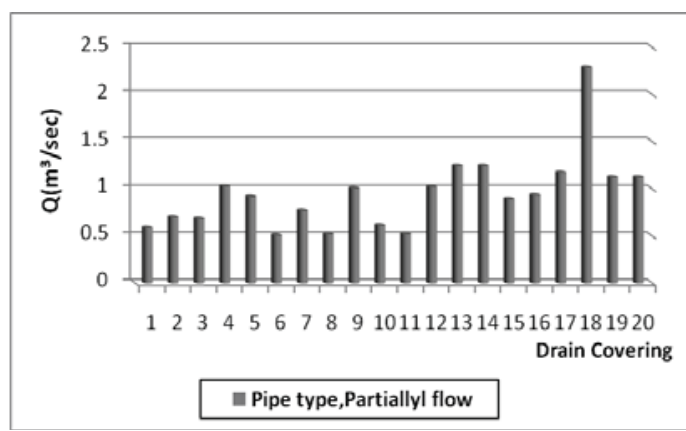

Fig (6): Values of (Q) for Selected Drains Covering

From the previous charts, the best choice due to the heading losses, velocity and discharge is the pipe type with partially flow but according to area and hydraulic radius is pipe type with full flow. The final result of hydraulic analysis, the best choice of all selected drain coverings is pipe type, partially flow.

\subsection{Analysis of the Economic Results}

The results of economic study are analyzed for the four alternatives which redesigned. However the best alternative in the point of economy is chosen in the two periods (the past and year 2013).

\subsubsection{Saving money for the redesign in the past \\ For all selected drain coverings, it is} found that the best alternative in economic point which saves largest value of money than the actual design is resulted from the case of pipe type, full flow, except the best alternative for the drains covering no.17, 18 is actual design because the cost of constructing the four alternatives is larger than the actual design. The percentage of saving money if this alternative was constructed in the past is shown in Fig (7).

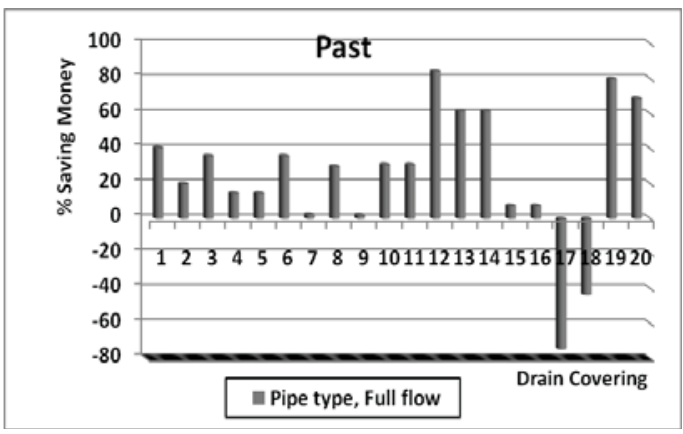

Fig (7): Percentage of Saving Money in the Past

\subsubsection{Saving money for the redesign in year 2013}

For all selected drains covering, it is found that the best alternative is resulted from the case of pipe type, full flow, except the best alternative for the drains covering no.17, 18 is actual design. The percentage of saving money if this alternative is constructing in year 2013 is shown in Fig (8).

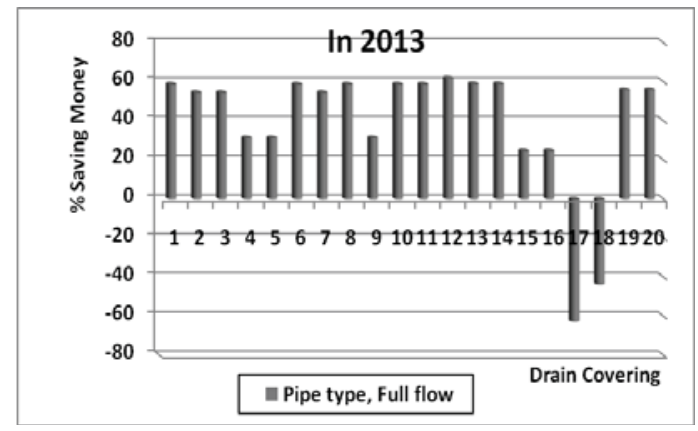

Fig (8): Percentage of Saving Money in Year 2013 


\subsubsection{Best choice due to hydraulic and economic studies :}

\section{a- In the past:}

For drains covering $(1,4,5,7,9,15 \& 16)$, it's found that the best choice is resulted from the alternative pipe type with full flow. The percentage of increasing $\mathrm{Q}$, decreasing $\mathrm{A}$ and money saving is shown in Fig (9).

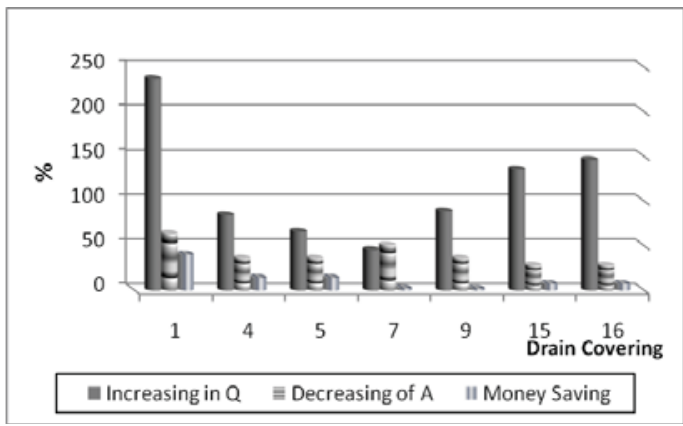

Fig (9): Percentage of Q, A and Money Saving for Pipe Type, Full Flow, in the Past

For drains covering $(2,3,6,8,10,11,12,13,14,19 \& 20)$, it's found that the best choice is resulted from the alternative pipe type with partially flow. The percentage of increasing $\mathrm{Q}$, decreasing $\mathrm{A}$ and money saving is shown in Fig (10).

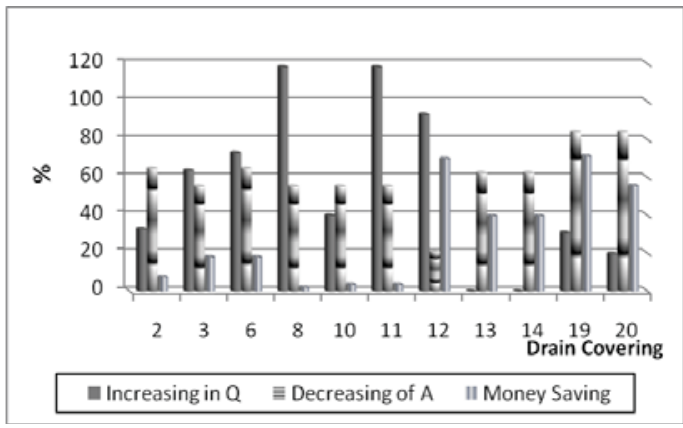

Fig (10): Percentage of Q, A and Money Saving for Pipe Type, Partially Flow, in the Past

For drains covering 17, 18 it's found that the best choice is resulted from the case of actual design.

From the data of these drain coverings it is found that head losses in actual design is very low because of the discharge is low and the area is large. But the velocity is not in the range and causes slitting. The design velocity is in the range as well as the slitting and scouring not occurred.

\section{b- In year 2013:}

For drains covering $(1,4,5 \& 9)$, it's found that the best choice is resulted from the alternative pipe type with full flow. The percentage of increasing $\mathrm{Q}$, decreasing $\mathrm{A}$ and money saving is shown in Fig (11).

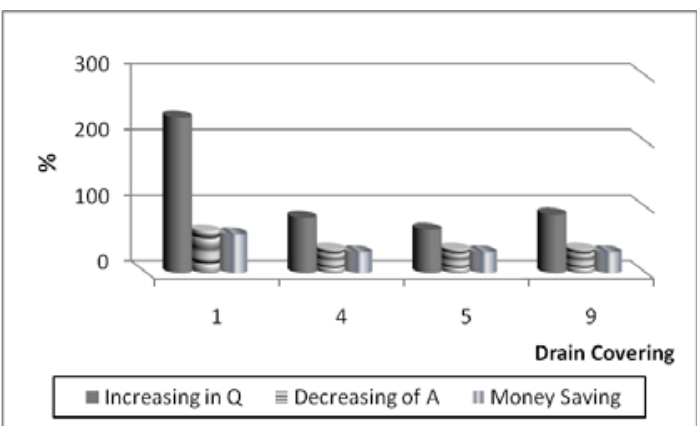

Fig (11): Percentage of Q, A and Money Saving for Pipe Type, Full Flow, in Year 2013

For drains covering $(2,3,6,7,8,10,11,12,13,14,15,16,19 \& 20)$, it's found that the best choice is resulted from the alternative pipe type and partially flow. The percentage of increasing Q, decreasing A and money saving is shown in Fig (12).

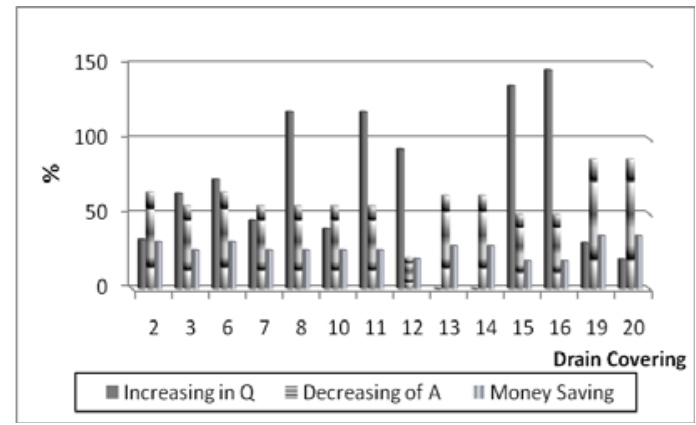

Fig (12): Percentage of $Q, A$ and Money Saving for Pipe Type, Full Flow, in Year 2013

For drain covering 17, 18 it's found that the best choice is resulted from the case of actual design. 


\section{EVALUATION OF DRAIN COVERINGS DESIGN IN EL-SHARKIA GOVERORATE, EGYPT}

Khairy, Mowafy, El-Nashar

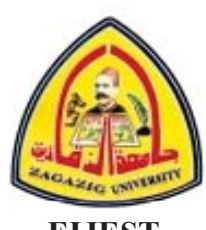

\section{CONCLUSIONS}

The covering is closed canal or industrial type. The main problems which lead to cover a drain are: to minimize the adverse impact of a polluted drain. In this research the twenty drains covering are selected in ElSharkia governorate, Egypt. Two evaluations are done of these drains covering according to hydraulic and economic points. The four alternatives are redesigned as pipe or box type with full or partially flow. Darcy equation is used to design the full flow alternatives and calculate the heading up. Hazen-Williams equation is used to design the partially flow alternatives. The economic study is also done. The best alternative is chosen for each drain coverings. The result for hydraulic evaluation, the best alternative is pipe type with partially flow for all drain coverings. The result for economic evaluation, the best alternative is pipe type with full flow for all drain coverings. The best alternative for both hydraulic and economy evaluations is different for the selected drain coverings. The best choice for drains $1,4,5$ and 9 is pipe type with full flow in the past and in year 2013. The best choice for drains $2,3,6,8,10,11,12,13,14,19$ and 20 is pipe type with partially flow in the past and in year 2013. The best choice for drain 7 is pipe type with full flow in the past and pipe type with partially flow in year 2013. The best choice for drains 15 and 16 is pipe type with full flow in the past and pipe type with partially flow in year 2013. The best choice for drains 17 and 18 is actual design in the past and in year 2013.

\section{REFERENCES}

[1] Christodoulou "Drop Manholes in Supercritical Pipelines", Journal of Irrigation and Drainage Engineering, 1991 Vol. 117, No.1, pp. 37-47.

[2] Dasika "New Approach to Design of Culverts", Journal of Irrigation and Drainage Engineering, ASCE, 1995, Vol. 121, No.3, pp. 261-264.

[3] Clarht and Charles "Experimental Test of a Model for Laminar Slurry Flow with Sedimentation" The Canadian Journal of Chemical Engineering, 1997, Vol. 75.

[4] Ferro "Applying Hypothesis of SelfSimilarity for Flow-Resistance Law of SmallDiameter Plastic Pipes", Journal of Irrigation and Drainage Engineering, 1997, Vol. 123.

[5] Hager and Guidice "Generalized Culvert Design Diagram", Journal of Irrigation and Drainage Engineering, 1998, Vol. 124, No.5, pp. 271-274.

[6] Bombardelli and Garcia "Hydraulic Design of Large-Diameter Pipes", Journal of Hydraulic Engineering, 2003, Vol. 129.

[7] Brasington and Smart "Close Range Digital Photogrammetric Analysis of Experimental Drainage Basin Evolution", Earth Surface Processes and Landforms, 2003, Vol. 28, pp.231-247

[8] Lee and Jin "Development of Program for Box Culverts Design", Proceedings of the $35^{\text {th }}$ Conference, Korean Society of Civil Engineers, 2003, pp. 2686-2689.

[9] Tao and Xiyun "Numerical Simulation of Drop Migration in Channel Flow under ZeroGravity", Chinese Journal of Mechanics Press, Beijing, China, 2004, Vol. 20, No.3

[10] American Association of state Highway and Transportation Officials "Model Drainage Manual", 2005, pp. 29-53.

[11] Wood "Water Hammer Analysis Essential, Easy and Efficient" Journal of Environmental Engineering, 2005.

[12] $\mathrm{Ku}$ and Jun "Development of Culvert Design Model", Proceedings of Korea Water Resources Association Conference, 2008, pp.645-649.

[13] Kang, Koo, Chun, Her, Park, and Yoo "Design of Drainage Culverts Considering Critical Storm Duration", Bios-stems Engineering, 2009, Vol. 104 No.3, pp. 425434.

[14] Korea Expressway Corporation "Road Design Guideline", 2009, Vol. 2, pp. 494-508. 
[15] Fahmy "Covering of Canals and Drains, Advantages and Disadvantages", Article submitted to a scientific committee of Public Works and Water Resources, 2011.

[16] Vatankhah and Easa "Simplified Accurate Solution for Design of Erodible Trapezoidal Channels", Journal of Hydrology Engineering, 2011, Vol. 16, pp.1943-5584

[17] Colin, Catherine and Fabre, "Turbulent Bubbly Flow in Pipe under Gravity and Microgravity Conditions" Journal of Fluid Mechanics, 2012, Vol. 711, pp. 469-515

[18] Yoo and Lee "Direct Determination of the Width or the Height for a Box Culvert Applying Dimensionless Equations", KSCE Journal of Civil Engineering (2012), Vol. 16, No. 7, pp.1302-1307

[19] Satterfield "Fundamentals of Hydraulics: Flow" National Environmental Services Center, 2010, Vol. 10.

[20] Cook, Bloomquist, Zink, and Ansley "Evaluation of Precast Box Culvert Systems" Final Report No. BC354 RPWO \#47, March 2002.

[21] Newnan "Engineering Economic Analysis", 2011, $11^{\text {th }}$ Edition, Oxford University,

http://summer.yonsei.ac.kr/files/course/Engine ering Economics[1].pdf 